\title{
De-escalation of Antiplatelet Therapy Retains P2Y12 Inhibitor After Percutaneous Coronary Intervention Among East Asians and Non-East Asians: A Meta-Analysis of Randomized Controlled Trials
}

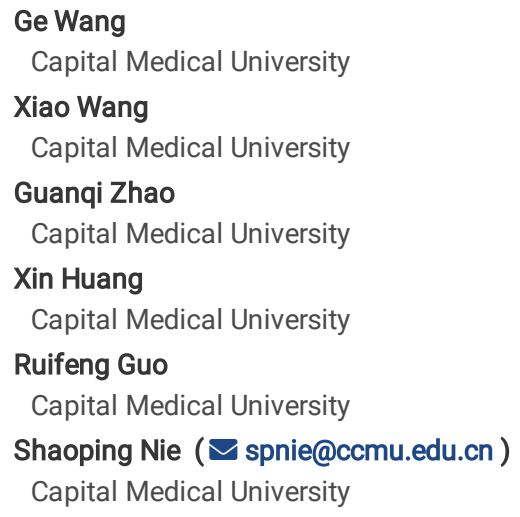

\section{Research Article}

Keywords: antiplatelet therapy, de-escalation, meta-analysis, percutaneous coronary intervention, randomized controlled trials

Posted Date: July 28th, 2021

DOl: https://doi.org/10.21203/rs.3.rs-709986/v1

License: (a) (1) This work is licensed under a Creative Commons Attribution 4.0 International License. Read Full License 


\section{Abstract}

Background: The impact of de-escalation of antiplatelet therapy retains P2Y12 inhibitor on major bleeding and ischemic outcomes after percutaneous coronary intervention (PCl) among East Asians and non-East Asians was unclear.

Methods: We systematically searched PubMed, Embase and the Cochrane Library for randomized controlled trials through September 2020. Eight trials were included, which studied de-escalation of DAPT (D-DAPT, switching to P2Y12 inhibitor monotherapy or decreasing the intensity of P2Y12 inhibitor after 1 to 3 months) versus 12 months standard DAPT (S-DAPT). The primary outcomes data were conducted with random effects models.

Results: Among 8 included trials with 37,775 patients, $62.6 \%$ of patients presented with acute coronary syndrome. The median follow-up duration ranged from 12 to 24 months. Compared with S-DAPT, D-DAPT was associated with a lower risk of major bleeding (RR=0.64, 95\%Cl: $0.47-0.88, p=0.006)$, but this was only observed among East-Asians ( $\mathrm{RR}=0.55,95 \% \mathrm{Cl}: 0.38-0.81, p=0.002)$. Among non-East Asians, the rate of major bleeding was similar between two groups ( $\mathrm{RR}=0.73,95 \% \mathrm{Cl}: 0.46-1.14, p=0.17$ ). There was no significant difference of MACE between D-DAPT and S-DAPT treatment among both East Asians $(\mathrm{RR}=0.84,95 \% \mathrm{Cl}: 0.66-1.08, p=0.18)$ and non-East Asians ( $\mathrm{RR}=0.89,95 \% \mathrm{Cl}: 0.79-1.00, p=0.05)$.

Conclusions: De-escalation strategy retains P2Y12 inhibitor after PCl was associated with reduced risk of bleeding events, which was only demonstrated in East Asians patients, but not in non-East Asians patients.

\section{Background}

Current, the American College of Cardiology (ACC)/American Heart Association (AHA), European, and Chinese guidelines all recommend that patients with acute coronary syndrome (ACS) undergoing percutaneous coronary interventions (PCI) should receive 12 months of dual antiplatelet therapy (DAPT) and those with stable coronary artery diseases (SCAD) undergoing PCl should receive 6 months of DAPT as a standard therapy (aspirin plus a P2Y12 inhibitor [16]). Given that most of bleeding complications might be occurred at 1 to 3 months after PCl, several large RCTs have evaluated the effect of de-escalation strategies [7-14], but the results are conflicting. Recently, several studies have reported that East Asian populations have different ischemia and bleeding profiles and might be more susceptible to bleeding [15-17], so they may not benefit from more potent antithrombotic strategies [7-10]. Therefore, we conducted this meta-analysis to evaluate the impact of de-escalation strategies retains P2Y12 inhibitor on both bleeding and ischemic events among East Asian and non-East Asian populations. We present the following article in accordance with the PRISMA reporting checklist.

\section{Methods}

Data Sources and Search Strategies

We searched PubMed, Embase and the Cochrane Library for randomized control trials (RCTs) through September 2020 by two independent investigators (G. W. and X. W.) without language restrictions. The following key words were used: "de-escalation" or "switch" and "percutaneous coronary intervention" or "PCl" or "acute coronary syndrome" or "ACS" and "antiplatelet therapy" or "prasugrel" or "ticagrelor" or "clopidogrel" (Figure 1).

Study Selection and Eligibility Criteria

Two investigators (G. W. and X. W.) independently assessed studies considered for inclusion by screening the titles and abstracts. The inclusion criteria were: (1) RCTs that compared de-escalation of DAPT (D-DAPT, switching to monotherapy that followed by P2Y12 receptor inhibitor, switching from a potent P2Y12 receptor inhibitor to clopidogrel or dose reduction of P2Y12 inhibitor) with standard DAPT (S-DAPT); (2) reporting on ischemic and bleeding events; (3) sample size $>500$ patients. Studies that focused on duration of DAPT for ACS undergoing PCl and reported on pharmacodynamics and pharmacokinetic of drugs were excluded.

Data Extraction and Quality Assessment

Data extraction and adjudication were performed independently by two investigators (G. W. and X. W.) using a standardized electronic form. Any discrepancies were judged and solved by a senior author (S.N.). We recorded the following information: time span, region, demographic characteristics, timing of de-escalation, switching strategy, number of events and participants, follow-up duration, and outcomes.

The potential risk of bias of selected RCTs was assessed using the Cochrane Risk of Bias Tool[18]. This meta-analysis was performed according to the Preferred Reporting Items for Systematic Review and Meta-Analysis (PRISMA) statement[19].

\section{Outcome Measures}

The primary outcome was major adverse cardiovascular events (MACE), including all-cause or cardiovascular death, myocardial infarction, repeat revascularization, stent thrombosis or stroke, which was reported by studies or integrated with ischemic events of each study. The primary safety outcome was major bleeding, defined as Bleeding Academic Research Consortium (BARC) $\geq 3$, or Thrombolysis in Myocardial Infarction (TIMI) major bleeding. Secondary efficacy outcomes included cardiovascular death, all-cause death, myocardial infarction (MI), definite or probable stent thrombosis, repeat revascularization, and stroke. According to ethnicity, we compared the outcomes between two strategies among East Asian and non-East Asian populations.

Statistical Analysis 
A random effect model was used to evaluate all outcomes of interest among East Asians and non-East Asians patients, which were reported as Risk Ratio (RR) with $95 \%$ confidence intervals (CI). The Cochran Q test and $\mathrm{I}^{2}$ statistic were used to assess heterogeneity. $\mathrm{I}^{2}$ statistic scores of $25 \%, 50 \%$, $75 \%$ respectively represents low, moderate and high heterogeneity. Sensitivity analyses were performed to evaluate the reasons for heterogeneity or the potential bias. Forest plot was used to evaluate the overall effect of trials, and funnel plots was used to assess the publication bias. All data analysis was performed with Cochrane Review Manager software (version 5.4). A 2-sided $p$ value $<0.05$ was considered statistically significant.

\section{Results}

From 7013 publications, 176 trials were assessed for full-text eligibility. After reading the full manuscripts, 168 studies were excluded, of which 53 studies were systematic reviews or meta-analysis, 31 studies were not RCTs, and 25 studies did not report on outcomes of interest. Finally, a total of 8 trials with 37775 patients were included in this meta-analysis (Figure 1). Overall, 23637 patients (62.6\%) presented as ACS, and the follow-up duration ranged from 12 to 24 months. Five trials evaluated a P2Y12 inhibitor monotherapy comparing with DAPT, and two trials evaluated a potent P2Y12 inhibitor switching to clopidogrel, and one trial evaluated switching the dose of prasugrel from $10 \mathrm{mg}$ to $5 \mathrm{mg}$. The detailed characteristics of all included studies are described in Table 1. The baseline clinical characteristics of each study are summarized in Table 2. Quality assessment were reported in Supplement Fig. A.3. Among the 8 included studies, $87.5 \%$ had high risk of blinding of intervention, and $100 \%$ had a low risk of blinding of outcome assessment.

Primary Efficacy and Safety Outcomes

We analyzed the effect of D-DAPT on major bleeding in 8 trials, a total of 679 major bleeding events occurred in all participants. Treatment with D-DAPT was associated with a lower risk of major bleeding ( $R R=0.64,95 \% \mathrm{Cl}: 0.47-0.88, p=0.006)$, but this was only observed in studies including East Asians patients $(1.2 \%$ vs. $2.3 \%, \mathrm{RR}=0.55,95 \% \mathrm{Cl}$ : $0.38-0.81, p=0.002)$. Among non-East Asians, the rate of major bleeding was similar in D-DAPT and S-DAPT groups $(1.6 \%$ vs. $2.0 \%, \mathrm{RR}=0.73,95 \% \mathrm{Cl}: 0.46-1.14, p=0.17$ ) (Figure 2).

All trials reported outcome of MACE. Treatment with de-escalation DAPT strategy was associated with a decreased risk of MACE (RR=0.88, $95 \% \mathrm{Cl}$ : 0.79 $0.98, p=0.02)$ in all participants. There was no significant difference of MACE between D-DAPT and S-DAPT treatment among both East Asians (RR=0.84, 95\% Cl: 0.66-1.08, $p=0.18$ ) and non-East Asians (RR=0.89, 95\% Cl: 0.79-1.00, $p=0.05)$ (Figure 3).

Cardiovascular Death and All-cause Death

Among both East Asians and non-East Asians, there was no statistically significance in cardiovascular death (7 trials with 21807 patients) between D-DAPT and S-DAPT groups (Figure 4). Similarly, no statistical difference of all-cause death (7 trials with 37129 patients) was observed in both East Asians and nonEast Asians (Figure 5).

Individual Cardiovascular Events

There were no statistical difference between D-DAPT and S-DAPT treatment in myocardial infarction (RR=0.79, 95\%Cl: 0.51-1.22, $p=0.29$ in East Asians; $\mathrm{RR}=0.99,95 \% \mathrm{Cl}: 0.86-1.14, p=0.84$ in non-East Asians), definite or probable stent thrombosis ( $\mathrm{RR}=1.41,95 \% \mathrm{Cl}: 0.59-3.33, p=0.44$ in East Asians; $\mathrm{RR}=0.93$, 95\% Cl: 0.69-1.26, $p=0.65$ in non-East Asians), repeat revascularization ( $\mathrm{RR}=1.15,95 \% \mathrm{Cl}: 0.91-1.46, p=0.24$ in East Asians; $\mathrm{RR}=0.98,95 \% \mathrm{Cl}$ : 0.82-1.18, $p=0.84$ in non-East Asians), and stroke (RR=0.95, 95\% Cl: 0.52-1.77, $p=0.88$ in East Asians; $\mathrm{RR}=0.99,95 \% \mathrm{Cl}$ : 0.55-1.76, $p=0.97$ in non-East Asians) (Figure 6).

Sensitivity Analyses

There was a slight trend but no significant difference in MACE among non-East Asians between D-DAPT and S-DAPT groups. While the TROPICAL-ACS trial included a part of patients who were re-escalated to prasugrel, which maybe affect the ischemic outcomes. After removal of the TROPICAL-ACS trial, the risk of ischemic outcomes was similar among non-East Asians who received de-escalation of DAPT or standard DAPT. The risk of major bleeding events was significantly lower with de-escalation of DAPT in initial pooled analysis, but substantial heterogeneity was presented. After removal of the GLOBAL-LEADERS trial, the risk of major bleeding was still lower with de-escalation of DAPT, while the heterogeneity $\mathrm{I}^{2}$ was reduced from $64 \%$ to $23 \%$. This may be due to large sample size of this trial. Among non-East Asians, the risk of major bleeding events was similar between D-DAPT group and S-DAPT group. However, due to unavailability of data of individual patients in TWILIGHT trial which included one-sixth Asian, we pooled this trial into the subgroup of non-East Asians. After removal of the TWILIGHT trial, the risk of major bleeding was still similar between two groups among non-East Asians.

\section{Discussion}

In the present meta-analysis, we found the following points: (1) Compared with S-DAPT, treatment with D-DAPT retains P2Y12 inhibitor was associated with lower risks of MACE and major bleeding complications; (2) Compared with S-DAPT, D-DAPT retains P2Y12 inhibitor was associated with a lower risk of major bleeding, but this was only observed among East Asians. Among non-East Asians, the rate of major bleeding was similar between two groups. (3) There were also no significant associations between D-DAPT retains P2Y12 inhibitor treatment with cardiovascular death, all-cause death and individual cardiovascular outcomes among East Asians and non-East Asians. Based on these results, compared with standard DAPT strategy, de-escalation of DAPT retains P2Y12 inhibitor treatment might be considered as an alternative DAPT strategy for East Asians.

It is well known that East Asians who received dual antiplatelet therapy after PCl have a higher risk of bleeding and a lower risk of ischemia[20]. This may be due to the lower body mass index (BMI) of the East Asians compared with non-East Asians. Previous studies have shown that obesity is associated with thrombosis[21], and it's a prethrombotic state that could cause a series of changes in the body to promote the formation of thrombus[22]. This may be one of

Page $3 / 12$ 
the reasons why the risk of ischemia in East Asians is lower than that in non-East Asians. Secondly, the genetic polymorphism between different races may also explain the profile of East Asians. Previous Multi-Ethnic Study of Atherosclerosis (MESA) studies [23]have shown that Blacks have highest levels of dysfunctional endothelial profile (such as factor VIII, D-Dimer, plasmin-antiplasmin, and von Willebrand factor), so they have the highest risk of thrombotic events, followed by Caucasians and Hispanics, and finally the Chinese participants. In addition, previous studies have shown that the level of inflammation can also affect thrombosis, and the level of inflammation in East Asians is lower than that in non-East Asians[24], which may also explain the low risk of ischemia in East Asians.

Previously, Bianco et al. (4 RCTS, 29089 patients) indicated that after short-term DAPT followed by P2Y 12 inhibitor monotherapy was associated with a lower risk of clinically relevant bleeding [odds ratio $(\mathrm{OR})=0.70,95 \% \mathrm{Cl}$ : $0.58-0.86$ ] for patients undergoing PCl, as compared with 12 months DAPT, without an increasing risk of 1 -year cardiovascular events $(\mathrm{OR}=0.90,95 \% \mathrm{Cl}$ : $0.79-1.03)$ [25]. Similarly results was observed in the analysis of Michelle et al. (5 trials, 32,145 patients) [26]. But none of them included the latest research. Moreover, the population of these studies is very wide, and they did not consider the differences of ethnicity. Our research confirmed that for East Asians, de-escalation strategy retains P2Y12 inhibitor was associated with a lower risk of major bleeding, but this was not observed among non-East Asians.

During one-to-three months after stenting, which belongs to the high incidence phase of ischemic events after PCl, the thrombotic risk outweighs the bleeding risk. While bleeding events generally occurred during a longer period after stent implantation, which belongs to the chronic phase. From the studies we included, it was noted that most of the de-escalation strategies start at one or three months after receiving dual antiplatelet therapy. As mentioned before, East Asians have a profile of high risk of bleeding. Therefore, in the chronic phase, downgrading of dual antiplatelet therapy, so as to reduce the degree of platelet inhibition, might reduce the risk of bleeding events among East Asians[7-10]. This is consistent with the results of our meta-analysis. Among nonEast Asians, we found that the effects of de-escalation of DAPT and standard DAPT on major bleeding events were similar and no significant difference. Although the TWILIGHT study[12] which across both East-Asians and non-East Asians showed downgrading therapy could reduce bleeding events with BARC $\geq 2$ in Asians and Caucasians, de-escalation of DAPT cannot reduce the risk of major bleeding (HR $=0.49,95 \mathrm{Cl} \%: 0.33-0.74)$. What's more, the study did not report the primary interest outcomes in East-Asians, the effect on major bleeding events between East-Asians and non-East Asians was not clear. And our sensitivity analysis showed that whether or not the study is removed, there is no significant effect on major bleeding outcomes of the non-East Asians subgroup. Therefore, the results of our meta-analysis can be considered reliable.

However, the results should be interpreted with caution. First, different definition might influence the incidence of outcomes, including MACE and major bleeding events. Second, various de-escalation strategies among different races included in this analysis might affect the pooled analysis results. Thirdly, the TWILIGHT trial included both East-Asians and non-East Asians. Due to lack of patient level data, we pooled all the data into non-East Asians group.

Limitations: This analysis has certain limitations. First, the rates of ischemic events were lower than anticipated in most of the included trials, resulting in limited statistical power for ischemia outcomes. Secondly, the included patients composed of both ACS and SCAD, and owing to lack of individual level data, we could not perform subgroup analysis for both groups. Thirdly, adherence of agents was not noted, which was a recognized and common factor associated with long-term outcomes. Fourth, the race was judged by the sites of the participating studies. Therefore, the possibility of the race mix-up was not excluded in those studies. And since patient category (East Asian versus other) is totally dependent upon study, it is possible that the racial differences are really just differences among the studies. Fifth, the current analysis just focused on major bleeding events, but minor bleeding was not reported, which more likely resulted in lower adherence of treatment in clinical practice. Finally, although we strictly performed the study searching and selection, some extent of potential publication or selection bias cannot be neglected.

\section{Conclusions}

De-escalation strategy after PCl was associated with reduced risk of bleeding events, which was only demonstrated in East Asians patients, but not in nonEast Asians patients. De-escalation of DAPT might be a safer and equally effective strategy for East Asians compared with standard DAPT strategy.

\section{Abbreviations}

\section{DAPT}

dual antiplatelet therapy

$\mathrm{PCl}$

percutaneous coronary intervention

D-DAPT

de-escalation of DAPT

S-DAPT

standard DAPT

MACE

major adverse cardiovascular event

RR

Risk Ratio

$\mathrm{Cl}$

confidence intervals

ACC / AHA 
American College of Cardiology / American Heart Association

ACS

acute coronary syndrome

SCAD

stable coronary artery diseases

RCTs

randomized control trials

BMI

body mass index

OR

odds ratio

\section{Declarations}

Ethics approval and consent to participate:

Not applicable.

Consent for publication:

Not applicable.

Availability of data and materials:

Not applicable.

Competing interests:

The authors declare that they have no competing interests.

Funding:

This study was funded by grants from Beijing Municipal Health Commission (grant numbers 2018-1-2061), Beijing Nova Program (grant numbers Z201100006820087), the Natural Science Foundation of Beijing, China (grant numbers 7191002), Beijing Municipal Administration of Hospitals (grant numbers ZYLX201710, DFL20180601), and Beijing Municipal Science and Technology Commission (grant numbers Z181100001718060).

\section{Authors' contributions:}

GW, XW and SN contributed to design the study and conduct the literature search and data extraction. GW and XW performed this meta-analysis. GW, XW, GZ, $\mathrm{XH}$ and $\mathrm{RG}$ contributed to interpretation of data. GW and XW wrote the draft of the manuscript, and all authors critically revised the manuscript and approved the final manuscript.

Acknowledgments:

Not applicable

\section{References}

1. Collet JP, Thiele H, Barbato E, Barthelemy O, Bauersachs J, Bhatt DL, Dendale P, Dorobantu M, Edvardsen T, Folliguet T et al: 2020 ESC Guidelines for the management of acute coronary syndromes in patients presenting without persistent ST-segment elevation. Eur Heart J 2020, 00:1-79.

2. Levine GN, Bates ER, Bittl JA, Brindis RG, Fihn SD, Fleisher LA, Granger CB, Lange RA, Mack MJ, Mauri L et al: 2016 ACC/AHA Guideline Focused Update on Duration of Dual Antiplatelet Therapy in Patients With Coronary Artery Disease: A Report of the American College of Cardiology/American Heart Association Task Force on Clinical Practice Guidelines. J Am Coll Cardiol 2016, 68(10):1082-1115.

3. Marco Valgimigli HcB, Robert A. Byrne, Jean-Philippe Collet, Francesco Costa, Anders Jeppsson, Peter Ju“ni: 2017 ESC focused update on dual antiplatelet therapy in coronary artery disease developed in collaboration with EACTS. European Heart Journal 2018, 39:213-254.

4. Junbo Ge YC, et,al.: Guideline and consensus for the management of patients with non-ST-elevation acute coronary syndrome(2016). Zhonghua Xin Xue Guan Bing Za Zhi 2017, 45(5):359-376.

5. Ruiyan Zhang WG, et,al.: 2019 Chinese Society of Cardiology (CSC) guidelines for the diagnosis and management of patients with ST-segment elevation myocardial infarction. Zhonghua Xin Xue Guan Bing Za Zhi 2019, 47(10):766-783.

6. Yanling Han WG, Xianghua Fu, et,al.: Guideline on the diagnosis and treatment of stable coronary artery disease. Zhonghua Xin Xue Guan Bing Za Zhi 2018, 46(9):680-694.

7. Kim H-S, Kang J, Hwang D, Han J-K, Yang H-M, Kang H-J, Koo B-K, Rhew JY, Chun K-J, Lim Y-H et al: Prasugrel-based deescalation of dual antiplatelet therapy after percutaneous coronary intervention in patients with acute coronary syndrome (HOST-REDUCE-POLYTECH-ACS): an open-label, multicentre, 
non-inferiority randomised trial. The Lancet 2020, 396(10257):1079-1089.

8. Hahn JY, Song YB, Oh JH, Chun WJ, Park YH, Jang WJ, Im ES, Jeong JO, Cho BR, Oh SK et al: Effect of P2Y12 Inhibitor Monotherapy vs Dual Antiplatelet Therapy on Cardiovascular Events in Patients Undergoing Percutaneous Coronary Intervention: The SMART-CHOICE Randomized Clinical Trial. JAMA 2019, 321(24):2428-2437.

9. Kim BK, Hong SJ, Cho YH, Yun KH, Kim YH, Suh Y, Cho JY, Her AY, Cho S, Jeon DW et al: Effect of Ticagrelor Monotherapy vs Ticagrelor With Aspirin on Major Bleeding and Cardiovascular Events in Patients With Acute Coronary Syndrome: The TICO Randomized Clinical Trial. JAMA 2020, 323(23):24072416.

10. Watanabe H, Domei T, Morimoto T, Natsuaki M, Shiomi H, Toyota T, Ohya M, Suwa S, Takagi K, Nanasato M et al: Effect of 1-Month Dual Antiplatelet Therapy Followed by Clopidogrel vs 12-Month Dual Antiplatelet Therapy on Cardiovascular and Bleeding Events in Patients Receiving PCl: The STOPDAPT-2 Randomized Clinical Trial. JAMA 2019, 321(24):2414-2427.

11. Mehran R, Baber U, Sharma SK, Cohen DJ, Angiolillo DJ, Briguori C, Cha JY, Collier T, Dangas G, Dudek D et al: Ticagrelor with or without Aspirin in HighRisk Patients after PCl. New England Journal of Medicine 2019, 381(21):2032-2042.

12. Vranckx P, Valgimigli M, Jüni P, Hamm C, Steg PG, Heg D, van Es GA, McFadden EP, Onuma Y, van Meijeren C et al: Ticagrelor plus aspirin for 1 month, followed by ticagrelor monotherapy for 23 months vs aspirin plus clopidogrel or ticagrelor for 12 months, followed by aspirin monotherapy for 12 months after implantation of a drug-eluting stent: a multicentre, open-label, randomised superiority trial. The Lancet 2018, 392(10151):940-949.

13. Thomas Cuisset PD, Jacques Quilici, ThomasW. Johnson, Ste'phanie Deffarges, Cle'mence Bassez, Guillaume Bonnet, Laurent Fourcade, Jean Philippe Mouret, Marc Lambert, Valentine Verdier, Pierre Emmanuel Morange, Marie Christine Alessi, and Jean Louis Bonnet: Benefit of switching dual antiplatelet therapy after acute coronary syndrome the TOPIC (timing of platelet inhibition after acute coronary syndrome) randomized study. European Heart Journal 2017, 38:3070-3078.

14. Sibbing D, Aradi D, Jacobshagen C, Gross L, Trenk D, Geisler T, Orban M, Hadamitzky M, Merkely B, Kiss RG et al: Guided deescalation of antiplatelet treatment in patients with acute coronary syndrome undergoing percutaneous coronary intervention (TROPICAL-ACS): a randomised, open-label, multicentre trial. Lancet 2017, 390(10104):1747-1757.

15. Kang J, Park KW, Palmerini T, Stone GW, Lee MS, Colombo A, Chieffo A, Feres F, Abizaid A, Bhatt DL et al: Racial Differences in Ischaemia/Bleeding Risk Trade-Off during Anti-Platelet Therapy: Individual Patient Level Landmark Meta-Analysis from Seven RCTs. Thromb Haemost 2019, 119(1):149-162.

16. Numasawa Y, Sawano M, Fukuoka R, Ejiri K, Kuno T, Shoji S, Kohsaka S: Antithrombotic Strategy for Patients with Acute Coronary Syndrome: A Perspective from East Asia. Journal of Clinical Medicine 2020, 9(6).

17. Urban P, Mehran R, Colleran R, Angiolillo DJ, Byrne RA, Capodanno D, Cuisset T, Cutlip D, Eerdmans P, Eikelboom J et al: Defining high bleeding risk in patients undergoing percutaneous coronary intervention: a consensus document from the Academic Research Consortium for High Bleeding Risk. Eur Heart J 2019, 40(31):2632-2653.

18. Ghogomu EA, Maxwell LJ, Buchbinder R, Rader T, Pardo Pardo J, Johnston RV, Christensen RD, Rutjes AW, Winzenberg TM, Singh JA et al: Updated method guidelines for cochrane musculoskeletal group systematic reviews and metaanalyses. J Rheumato/ 2014, 41(2):194-205.

19. David Moher LS, Mike Clarke, Davina Ghersi, Alessandro Liberati, Mark Petticrew, Paul Shekelle, Lesley A Stewart Preferred reporting items for systematic review and meta-analysis protocols (PRISMA-P) 2015 statement. Systematic Reviews 2015, 4(1):1.

20. Kang J, Kim HS: The Evolving Concept of Dual Antiplatelet Therapy after Percutaneous Coronary Intervention: Focus on Unique Feature of East Asian and "Asian Paradox". Korean Circ J 2018, 48(7):537-551.

21. Samad F, Ruf W: Inflammation, obesity, and thrombosis. Blood 2013, 122(20):3415-3422.

22. Kornblith LZ, Howard B, Kunitake R, Redick B, Nelson M, Cohen MJ, Callcut R: Obesity and clotting: Body mass index independently contributes to hypercoagulability after injury. J Trauma Acute Care Surg 2015, 78(1):30-36; discussion 37-38.

23. Lutsey PL, Cushman M, Steffen LM, Green D, Barr RG, Herrington D, Ouyang P, Folsom AR: Plasma hemostatic factors and endothelial markers in four racial/ethnic groups: the MESA study. Journal of Thrombosis and Haemostasis 2006, 4(12):2629-2635.

24. Veeranna V, Zalawadiya SK, Niraj A, Kumar A, Ference B, Afonso L: Association of novel biomarkers with future cardiovascular events is influenced by ethnicity: results from a multi-ethnic cohort. Int J Cardiol 2013, 166(2):487-493.

25. Bianco M, Careggio A, Destefanis P, Luciano A, Perrelli MG, Quadri G, Rossini R, Campo G, Vizzari G, D'Ascenzo F et al: P2Y12 inhibitors monotherapy after short course of dual antiplatelet therapy in patients undergoing percutaneous coronary intervention: a meta-analysis of randomized clinical trials including 29089 patients. Eur Heart J Cardiovasc Pharmacother 2020.

26. Michelle L. O'Donoghue M, Sabina A. Murphy, Marc S. Sabatine: The Safety and Efficacy of Aspirin Discontinuation on a Background of a P2Y12 Inhibitor in Patients after Percutaneous Coronary Intervention: A Systematic Review and Meta-Analysis. Circulation 2020, $142(6): 538-545$.

\section{Tables}

Table1 Study design and clinical characteristics of included studies 


\begin{tabular}{|c|c|c|c|c|c|c|c|c|c|c|c|}
\hline $\begin{array}{l}\text { Study } \\
\text { name }\end{array}$ & Period & Reigon & Center & Population & $\begin{array}{l}\text { D- } \\
\text { DAPT }\end{array}$ & $\begin{array}{l}\text { S- } \\
\text { DAPT }\end{array}$ & $\begin{array}{l}\text { Timing of } \\
\text { de- } \\
\text { escalation }\end{array}$ & $\begin{array}{l}\text { Switching } \\
\text { strategy }\end{array}$ & MACE & Bleeding & $\begin{array}{l}\text { Follow- } \\
\text { up } \\
\text { time }\end{array}$ \\
\hline $\begin{array}{l}\text { HOST- } \\
\text { REDUCE- } \\
\text { POLYTECH- } \\
\text { ACS }\end{array}$ & $\begin{array}{l}2014- \\
2018\end{array}$ & Korea & $M$ & ACS & 1170 & 1168 & $\begin{array}{l}1 \text { month } \\
\text { after PCl }\end{array}$ & $\begin{array}{l}\text { Prasugrel } \\
10 \mathrm{mg}-5 \mathrm{mg}\end{array}$ & $\begin{array}{l}\text { Cardiac death+ } \\
\text { Ml+ stent } \\
\text { thrombosis+ } \\
\text { ischemic stroke }\end{array}$ & BARC & $1 Y$ \\
\hline TWILIGHT & $\begin{array}{l}2015- \\
2017\end{array}$ & $\begin{array}{l}\text { North } \\
\text { America+ } \\
\text { Europe+ } \\
\text { Asia }\end{array}$ & $M$ & $A C S+S C A D$ & 3555 & 3564 & $\begin{array}{l}3 \text { months } \\
\text { after } \\
\text { discharge }\end{array}$ & $\begin{array}{l}\text { ticagrelor } \\
\text { monotherapy }\end{array}$ & \begin{tabular}{l}
\multicolumn{1}{c}{ all-cause } \\
death+ nonfatal \\
Ml+ nonfatal \\
stroke
\end{tabular} & BARC & $\begin{array}{l}15 \\
\text { mon }\end{array}$ \\
\hline TICO & $\begin{array}{l}2015- \\
2018\end{array}$ & Korea & $M$ & ACS & 1527 & 1529 & $\begin{array}{l}\text { 3-months } \\
\text { after } \\
\text { DAPT }\end{array}$ & $\begin{array}{l}\text { ticagrelor } \\
\text { monotherapy }\end{array}$ & $\begin{array}{l}\text { death+ Ml+ stent } \\
\text { thrombosis+ } \\
\text { stroke+ target- } \\
\text { vessel } \\
\text { revascularization }\end{array}$ & TIMI & $1 Y$ \\
\hline TOPIC & $\begin{array}{l}2014- \\
2016\end{array}$ & France & S & ACS & 323 & 323 & $\begin{array}{l}1 \text { month } \\
\text { after ACS }\end{array}$ & $\begin{array}{l}\text { ticagrelor } \\
\text { /prasugrel- } \\
\text { clopidogrel }\end{array}$ & $\begin{array}{l}\text { cardiovascular } \\
\text { death+ unplanned } \\
\text { urgent coronary } \\
\text { revascularization+ } \\
\text { stroke }\end{array}$ & TIMI & $1 Y$ \\
\hline $\begin{array}{l}\text { TROPICAL- } \\
\text { ACS }\end{array}$ & $\begin{array}{l}2013- \\
2016\end{array}$ & European & $M$ & ACS & 1304 & 1306 & $\begin{array}{l}\mathrm{P}(1-\text {-week }) \\
+\mathrm{C}(1- \\
\text { week }) \text { and } \\
\text { PFT- } \\
\text { guided } \\
\text { therapy } \\
\text { from day } \\
14\end{array}$ & $\begin{array}{l}\text { prasugrel- } \\
\text { clopidogrel } \\
\text { (PFT-guided) }\end{array}$ & $\begin{array}{l}\text { cardiovascular } \\
\text { death+ Ml+ stroke }\end{array}$ & BARC & $1 Y$ \\
\hline $\begin{array}{l}\text { SMART } \\
\text { CHOICE }\end{array}$ & $\begin{array}{l}2014- \\
2018\end{array}$ & Korea & $M$ & $S C A D+A C S$ & 1495 & 1498 & $\begin{array}{l}\text { 3-months } \\
\text { after } \\
\text { DAPT }\end{array}$ & $\begin{array}{l}\text { a P2Y12 } \\
\text { inhibitor } \\
\text { monotherapy }\end{array}$ & $\begin{array}{l}\text { all-cause } \\
\text { mortality+ Ml+ } \\
\text { stroke. }\end{array}$ & BARC & $1 Y$ \\
\hline $\begin{array}{l}\text { STOPDAPT- } \\
2\end{array}$ & $\begin{array}{l}2015- \\
2017\end{array}$ & Japan & $M$ & $S C A D+A C S$ & 1523 & 1522 & $\begin{array}{l}1 \text { month } \\
\text { after } \\
\text { DAPT }\end{array}$ & $\begin{array}{l}\text { Clopidogrel } \\
\text { monotherapy }\end{array}$ & $\begin{array}{l}\text { cardiovascular } \\
\text { death+ Ml+ } \\
\text { definite stent } \\
\text { thrombosis+ } \\
\text { stroke }\end{array}$ & BARC & $1 Y$ \\
\hline $\begin{array}{l}\text { GLOBAL- } \\
\text { LEADERS }\end{array}$ & $\begin{array}{l}2013- \\
2015\end{array}$ & European & $M$ & $S C A D+A C S$ & 7980 & 7988 & $\begin{array}{l}1 \text { month } \\
\text { after } \\
\text { DAPT }\end{array}$ & $\begin{array}{l}\text { ticagrelor } \\
\text { monotherapy }\end{array}$ & $\begin{array}{l}\text { all-cause } \\
\text { mortality+ stroke+ } \\
\text { new Q-wave MI }\end{array}$ & BARC & $2 Y$ \\
\hline
\end{tabular}

RCT: randomized controlled trials; ACS: acute coronary syndrome; SCAD: stable coronary artery disease; PCl: percutaneous coronary intervention; M: multicenter; S: single center; MACE: major adverse cardiovascular events; BARC: Bleeding Academic Research Consortium; TIMI: Thrombolysis In Myocardial Infraction major bleeding; Y: year; mon: month; P: prasugrel; T:ticagrelor; PFT: platelet function testing; DAPT: dual antiplatelet therapy; D-DAPT: deescalation of dual antiplatelet therapy; S-DAPT: standard dual antiplatelet therapy; MI: myocardial infraction.

Table 2 Baseline clinical characteristics of included studies

\begin{tabular}{|c|c|c|c|c|c|c|c|c|}
\hline Study name & $\begin{array}{l}\text { Age (y; } \\
\mathrm{m})\end{array}$ & $\begin{array}{l}\text { Female } \\
(\mathrm{n}, \%)\end{array}$ & $\begin{array}{l}\mathrm{BMI} \\
\text { (kg/m2; } \\
\mathrm{m})\end{array}$ & $\begin{array}{l}\text { DM }(n, \\
\%)\end{array}$ & $\begin{array}{l}\text { Current smoker } \\
(\mathrm{n}, \%)\end{array}$ & Prior MI (n, \%) & $\begin{array}{l}\text { Chronic kidney disease } \\
(\mathrm{n}, \%)\end{array}$ & $\begin{array}{l}\text { ACS }(n, \\
\%)\end{array}$ \\
\hline $\begin{array}{l}\text { HOST-REDUCE- } \\
\text { POLYTECH-ACS }^{[7]}\end{array}$ & 58.8 & $\begin{array}{l}252 \\
(10.7)\end{array}$ & 25.8 & $\begin{array}{l}990 \\
(42.3)\end{array}$ & $838(35.8)$ & $90(3.8)$ & $64(2.7)$ & $\begin{array}{l}2338 \\
(100)\end{array}$ \\
\hline TWILIGHT $^{[11]}$ & 65.2 & $\begin{array}{l}1698 \\
(23.9)\end{array}$ & 28.6 & $\begin{array}{l}2620 \\
(36.8)\end{array}$ & $1548(21.8)$ & $2040(28.7)$ & 1145 (16.8) & $\begin{array}{l}4614 \\
(64.8)\end{array}$ \\
\hline $\operatorname{TICO}^{[9]}$ & 61 & $\begin{array}{l}628 \\
(20.5)\end{array}$ & 24.9 & $\begin{array}{l}835 \\
(27.3)\end{array}$ & NA & $113(3.7)$ & $620(20.3)$ & $\begin{array}{l}3056 \\
(100)\end{array}$ \\
\hline TOPIC $^{[13]}$ & 60 & $114(18)$ & 27.2 & 177 (27) & $286(44)$ & NA & NA & $\begin{array}{l}646 \\
(100)\end{array}$ \\
\hline TROPICAL-ACS ${ }^{[14]}$ & 58.8 & $\begin{array}{l}2052 \\
(78.6)\end{array}$ & 28.3 & $\begin{array}{l}527 \\
(20.2)\end{array}$ & $1182(45.3)$ & $293(11.2)$ & $67(2.6)$ & $\begin{array}{l}2610 \\
(100)\end{array}$ \\
\hline SMART CHOICE ${ }^{[8]}$ & 64.5 & $\begin{array}{l}795 \\
(26.6)\end{array}$ & 24.6 & $\begin{array}{l}1122 \\
(37.5)\end{array}$ & $791(26.4)$ & $127(4.2)$ & $97(3.2)$ & $\begin{array}{l}1741 \\
(58.2)\end{array}$ \\
\hline STOPDAPT- $2^{[10]}$ & 68.6 & $\begin{array}{l}672 \\
(22.3)\end{array}$ & 24.3 & $\begin{array}{l}1159 \\
(38.5)\end{array}$ & $710(23.6)$ & $406(13.5)$ & $166(5.5)$ & $\begin{array}{l}1148 \\
(38.2)\end{array}$ \\
\hline GLOBAL-LEADERS $^{[12]}$ & 64.6 & $\begin{array}{l}3714 \\
(23.3)\end{array}$ & 28.2 & $\begin{array}{l}4038 \\
(25.3)\end{array}$ & $4169(26.1)$ & $3710(23.2)$ & $2171(13.6)$ & $\begin{array}{l}7484 \\
(46.9)\end{array}$ \\
\hline
\end{tabular}


BMI: Body-mass index; DM: diabetes mellitus; MI: myocardial infraction; ACS: acute coronary syndrome; STEMI: ST-segment elevation myocardial infraction; y: years; m: mean; n: number; NA: not available

\section{Figures}

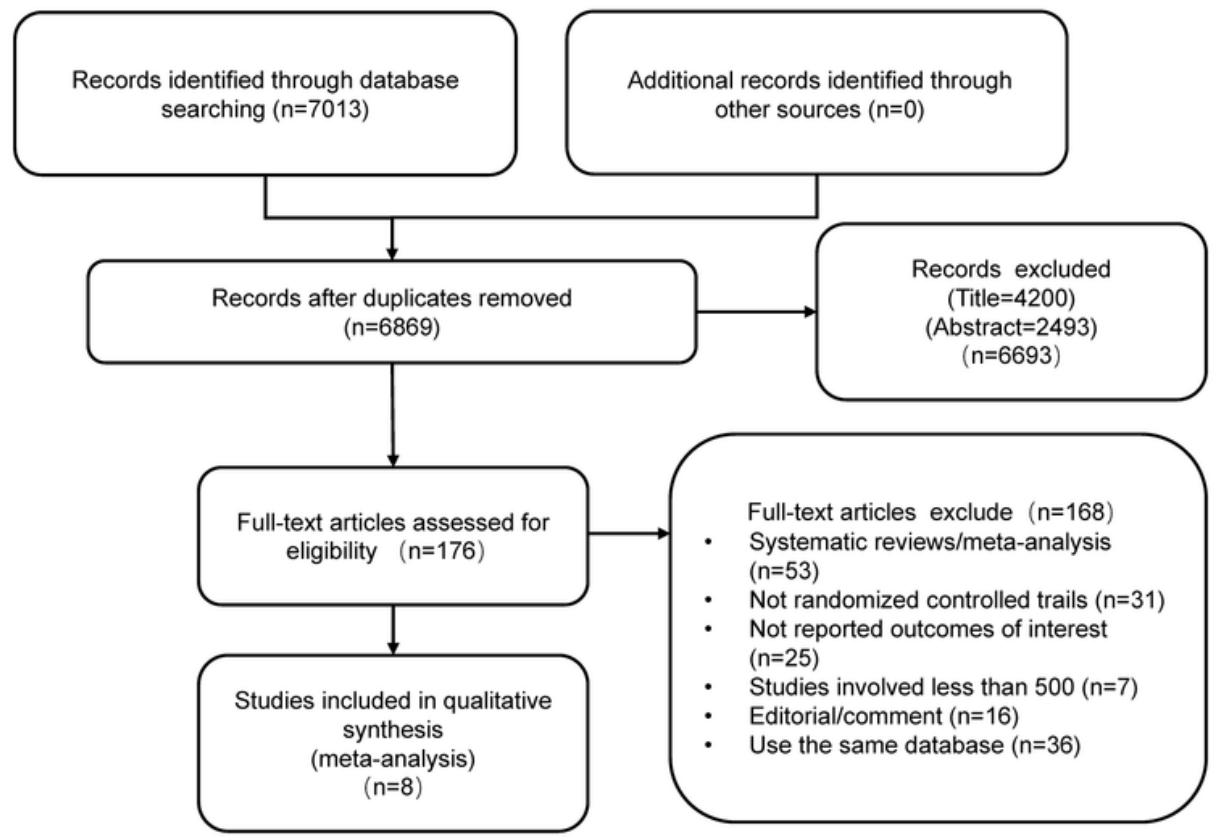

\section{Figure 1}

Flow chart of the study selection process of meta-analysis 


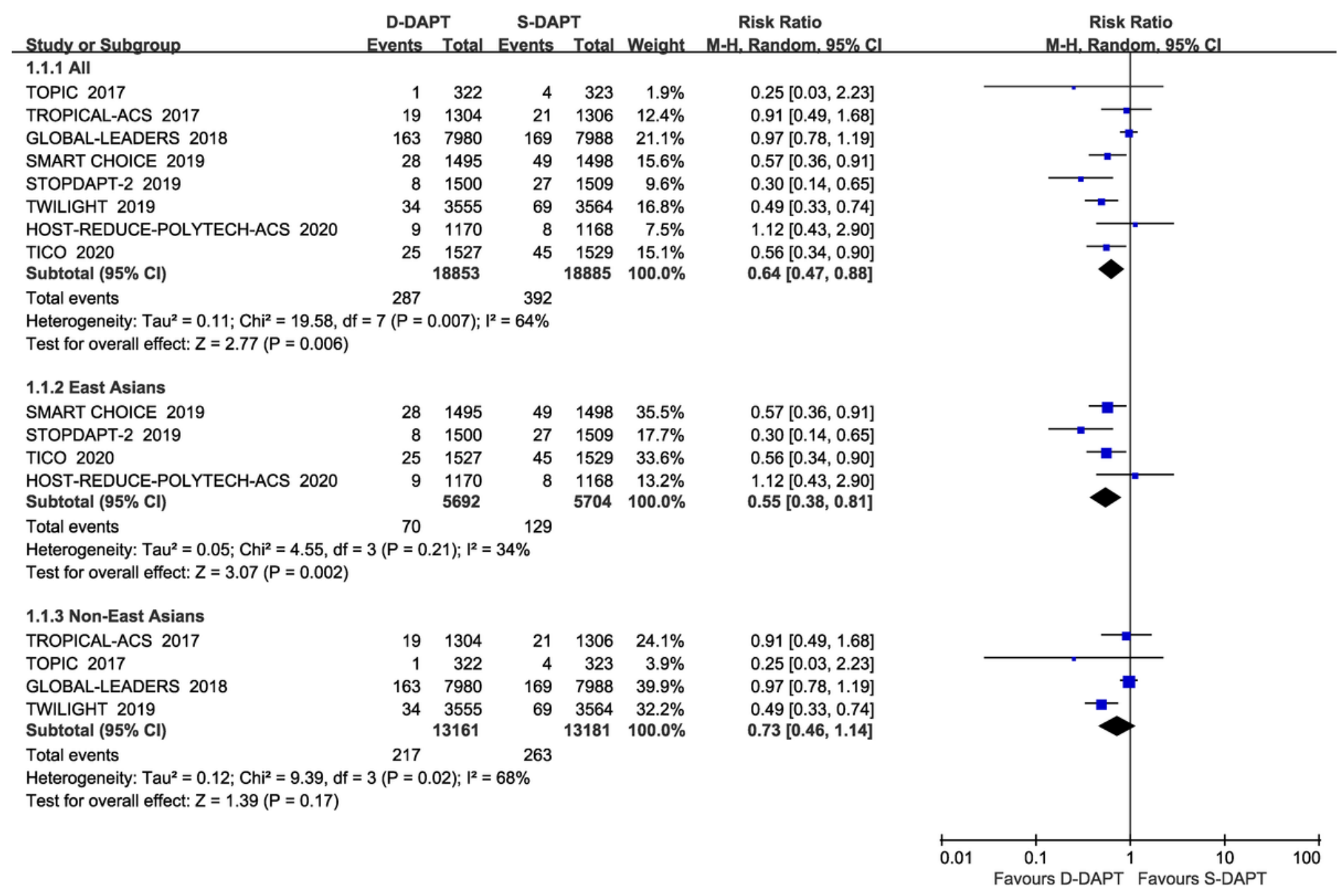

Figure 2

Forest plot of the risk estimates for major bleeding in patients treated with de-escalation of dual antiplatelet therapy (D-DAPT) compared to standard DAPT (S-DAPT) 


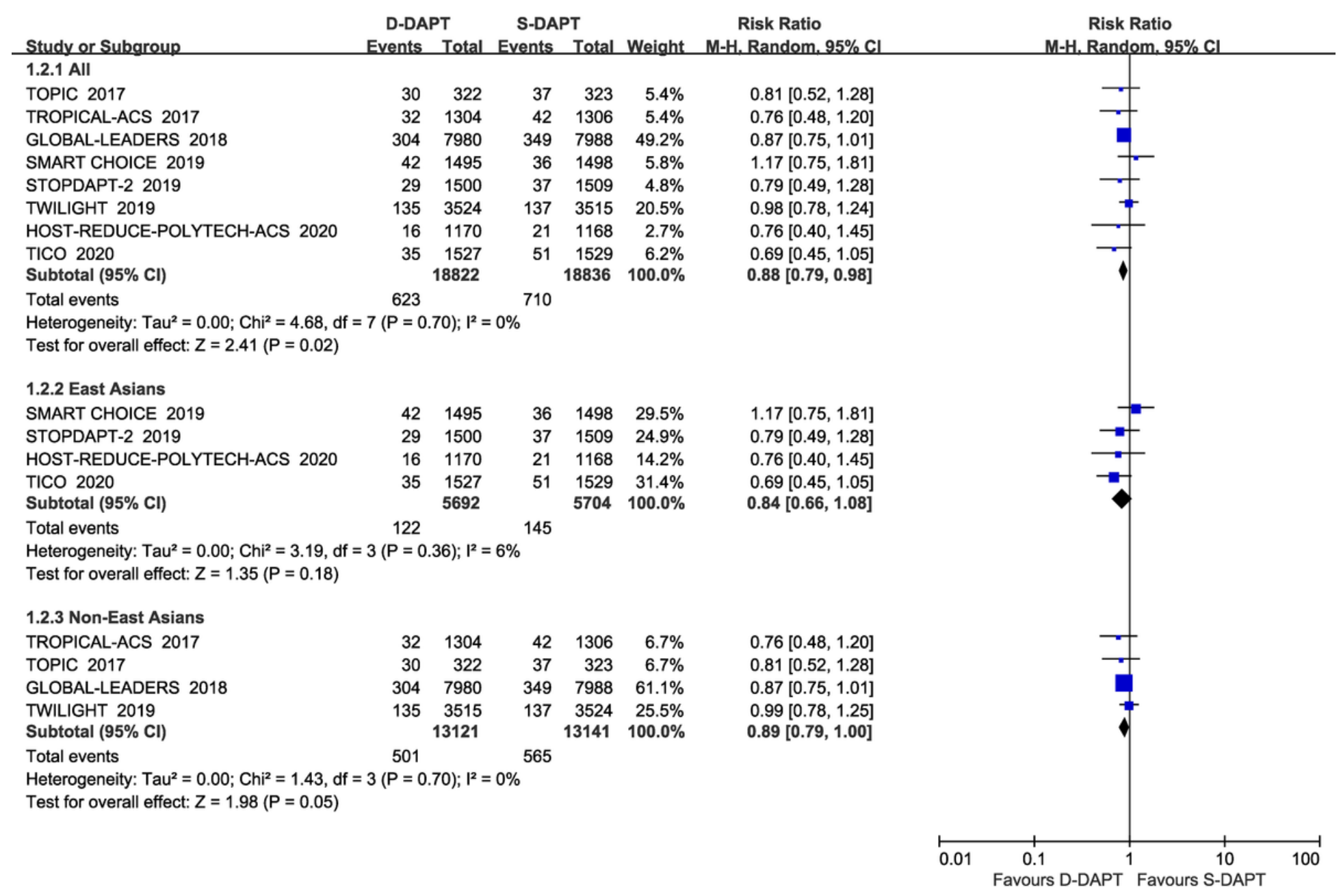

Figure 3

Forest plot of the risk estimates for major adverse cardiovascular events (MACE) in patients treated with de-escalation of dual antiplatelet therapy (D-DAPT) compared to standard DAPT (S-DAPT)

D-DAPT S-DAPT Risk Ratio

Risk Ratio

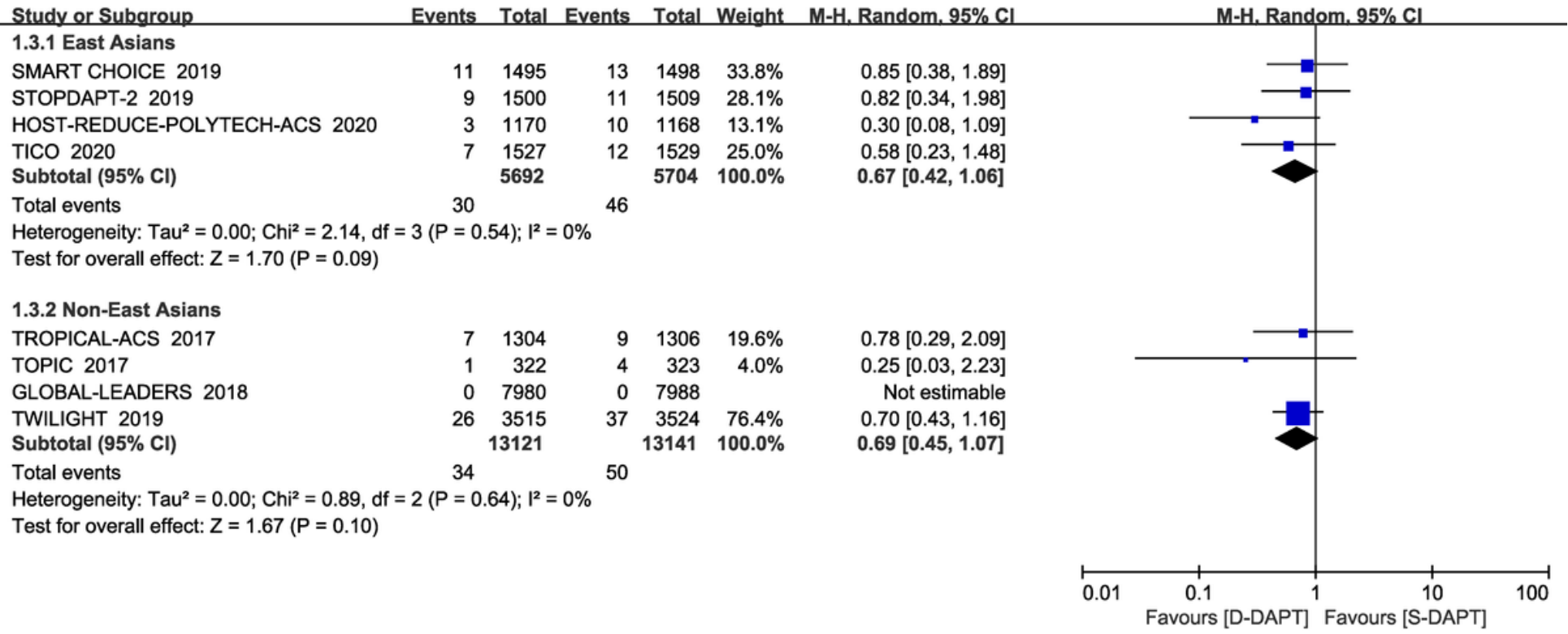

Figure 4

Forest plot of the risk estimates for cardiovascular death in patients treated with de-escalation of dual antiplatelet therapy (D-DAPT) compared to standard DAPT (S-DAPT) 


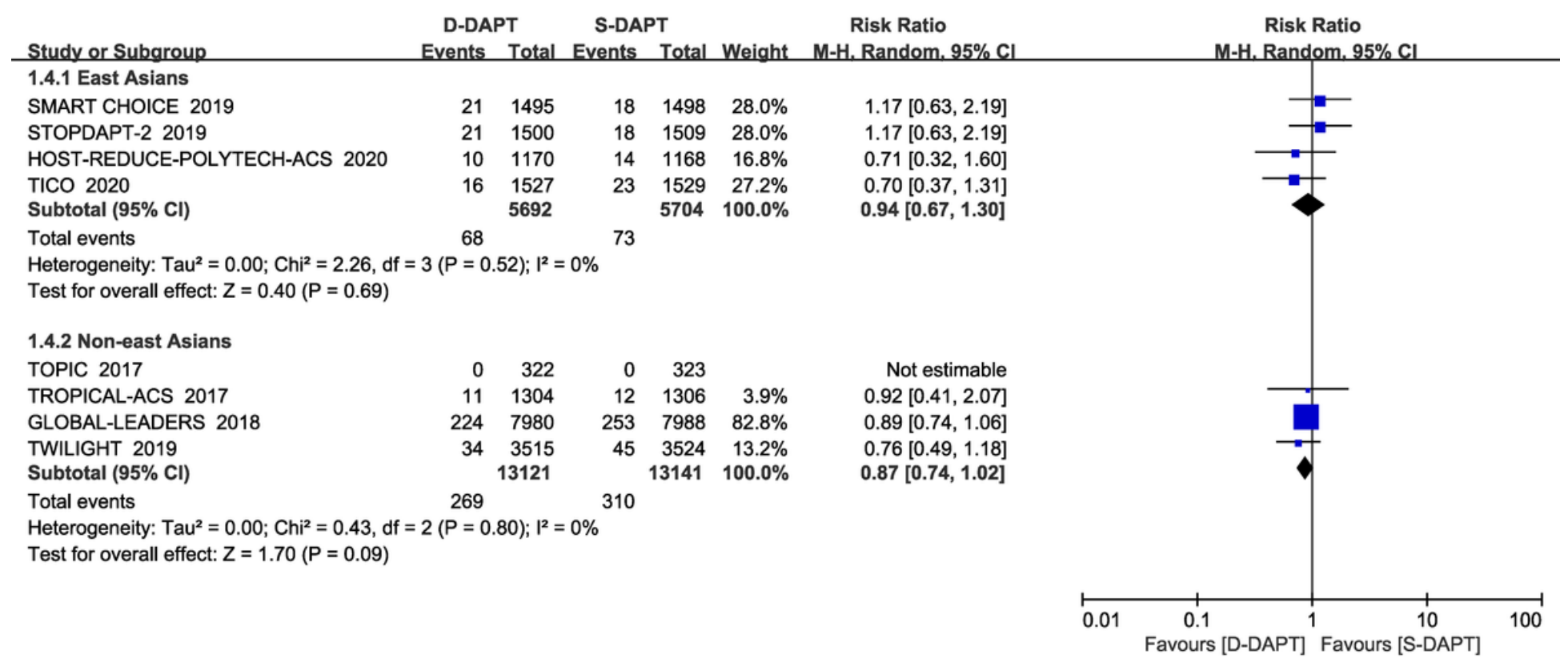

\section{Figure 5}

Forest plot of the risk estimates for all-cause death in patients treated with de-escalation of dual antiplatelet therapy (D-DAPT) compared to standard DAPT (S-DAPT)
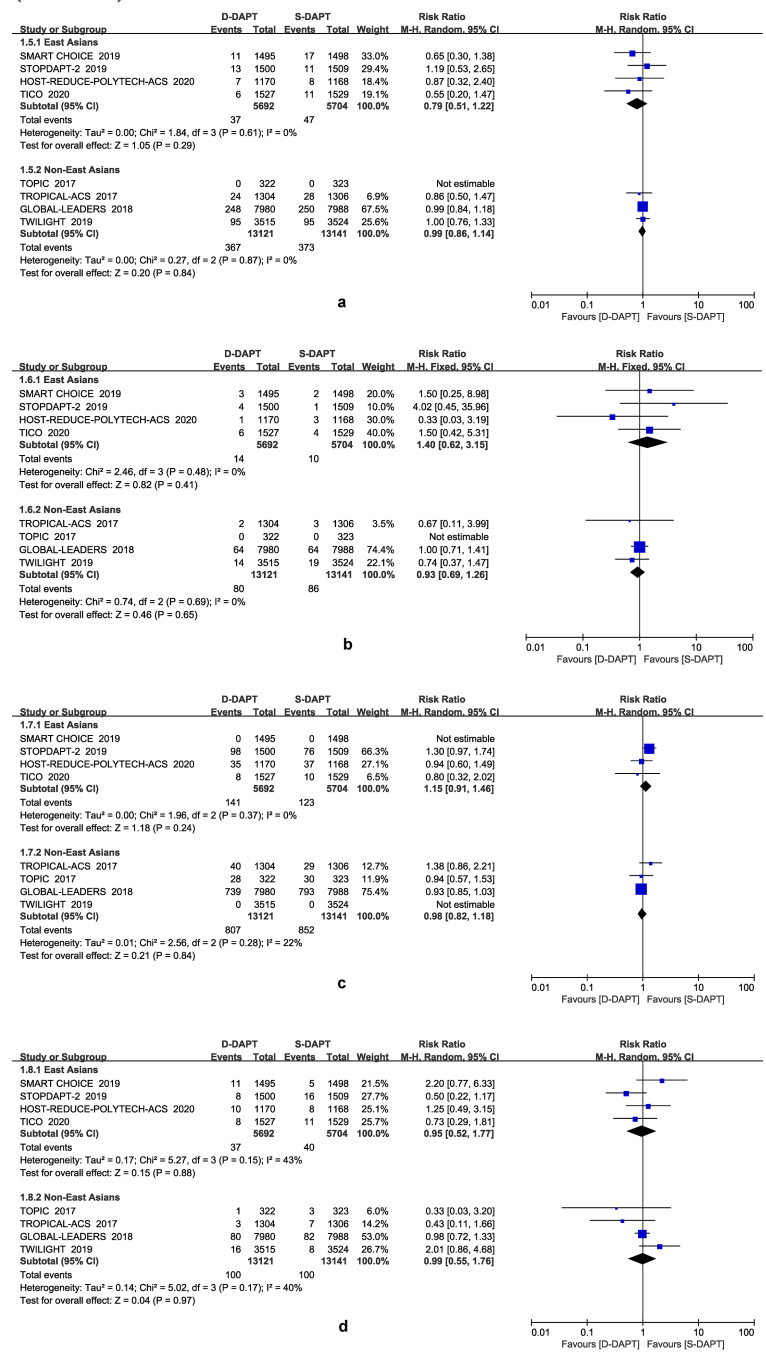

Figure 6 
Forest plot of the risk estimates for individual cardiovascular events in patients treated with de-escalation of dual antiplatelet therapy (D-DAPT) compared to standard DAPT (S-DAPT). a. myocardial infraction (MI). b. stent thrombosis. c. repeat revascularization. d. stroke

\section{Supplementary Files}

This is a list of supplementary files associated with this preprint. Click to download.

- Supplementarymaterial.pdf 